\title{
Articulando modelos de alinhamento estratégico de tecnologia da informação
}

\author{
Linking information technology strategic alignmnet models
}

\author{
Luiz Antonio Joia ${ }^{1}$ \\ José Geraldo Andrade de Souza²
}

\section{Resumo}

O conceito de tecnologia da informação (TI) vem ganhando importância para as organizações. O uso eficiente da TI e a integração entre sua estratégia e a estratégia de negócios vão além da idéia de que se trate de uma mera ferramenta de automação de processos e de aumento da produtividade empresarial. Através do alinhamento estratégico de TI, busca-se o ajuste tanto das estratégias de negócios e de TI, quanto das estruturas internas da empresa. Para isso, diversos modelos desse alinhamento têm sido propostos. Este artigo analisa oito deles. $O$ objetivo é propor uma articulação entre esses modelos de alinhamento estratégico, de modo a integrar os seus vários elementos comuns e complementares, propondo um novo modelo conceitual teórico, via triangulação analítico-teórica. O modelo proposto mantém os principais conceitos encontrados nos modelos de alinhamento estratégico de TI analisados, consolidando e explicitando os conceitos propostos individualmente por esses modelos.

Palavras-chave: alinhamento estratégico da tecnologia da informação; tecnologia da informação; estratégia empresarial; triangulação analítico-teórica.

Abstract

The concept of Information Technology (IT) is becoming increasingly important for the organizations. The effective use of IT in firms, as well as the integration between the IT strategy and the business strategy of a company, have surpassed the idea of IT as a simple tool for process automation and productivity growth. The Strategic Alignment of Information Technology aims at adjusting both the Business and Information Technology's strategies of a company and its internal structures. As such, several Models of Strategic Alignment of IT have been proposed. This article analyzes eight of them. The goal is to propose an articulation among these main existing models of strategic alignment of IT, integrating its common and complementary elements and proposing a new theoretical conceptual model, via an analytic-theoretical triangulation. The proposed model keeps the main concepts found out in the IT Strategic Alignment models analyzed, consolidating and highlighting the issues individually proposed by these Business-IT alignment models.

Keywords: information technology strategic alignment; information technology; business strategy; analytictheoretical triangulation.

\footnotetext{
${ }^{1}$ D.Sc. em Engenharia de Produção - COPPE/UFRJ M.Sc. em Engenharia Civil - COPPE/UFRJ M.Sc. em Management Studies - Oxford University Engenheiro de Fortificação e Construção - Instituto Militar de Engenharia. Professor da Escola Brasileira de Administração Pública e de Empresas da Fundação Getulio Vargas (EBAPE/FGV).Endereço: Praia de Botafogo, 190 - sala 526 - Botafogo - Rio de Janeiro/RJ - Brasil - CEP: 22250-900. E-mail: luiz.joia@fgv.br

${ }^{2}$ Mestre em gestão empresarial pela Escola Brasileira de Administração Pública e de Empresas da Fundação Getulio Vargas (EBAPE/FGV). Gerente de Projetos Especiais do Banco BMG. Endereço: Rua Assunão 475 - apt 501 - Sion - Belo Horizonte - Minas Gerais - Brasil - CEP: 30320020. Email:jgasouza@globo.com

Artigo submetido em novembro de 2007 e aceito em janeiro de 2008.
} 


\section{Introdução}

O conceito de tecnologia da informação (TI) é bastante amplo. Ele abrange tanto aspectos eminentemente tecnicistas - como sistemas de informação e programas aplicativos (software), equipamentos e seus dispositivos periféricos (hardware), telecomunicações e redes de computadores - como outros aspectos de igual importância, como recursos humanos (peopleware), modelos de gestão e contextos organizacionais (ver, p.ex.: LAURINDO et al, 2001; LUCAS Jr.; BAROUDI, 1994; ORLIKOWSKI; ROBEY, 1991; REZENDE, 2002).

Este conceito abrangente vem ganhando importância para as organizações, na medida em que estas esperam que a TI desempenhe um papel estratégico, não só dando suporte a suas operações de negócio, mas também viabilizando novas estratégias empresariais (LAURINDO et al, 2001; REICH; BENBASAT, 1996; TEO; KING, 1997). Para alguns autores, a TI deve ser vista como um recurso corporativo que poderia tanto apoiar as estratégias em nível operacional, quanto direcioná-las num nível mais alto, trazendo vantagem competitiva para os negócios (ver, p.ex.: BRODBECK et al, 2005; CIBORRA, 1997; HIRSCHHEIM; SABHERWAL, 2001).

A partir dessas expectativas, surgem questionamentos sobre os resultados advindos dos investimentos em tecnologia da informação realizados pelas organizações (BRYNJOLFSSON, 1993; STRASSMANN, 1997; WEILL; OLSON, 1989). Henderson e Venkatraman (1993), por exemplo, levantam dúvidas sobre como conciliar as evidências de ganhos mínimos de produtividade com os investimentos significativos realizados em TI pelas organizações. Como resposta, estes e outros autores (p.ex.: LAURINDO et al, 2001; BRODBECK et al, 2005) argumentam que a falta de habilidade das organizações para obterem retornos satisfatórios dos investimentos feitos em TI se deve, em parte, à falta de alinhamento entre as estratégias de negócio e as de TI.

Luftman (2000) define alinhamento estratégico (AE) como as atividades executadas de forma coordenada pela gerência da organização, com o objetivo de alcançar suas metas através da coordenação de várias áreas funcionais, tais como: tecnologia da informação, finanças, marketing, recursos humanos, manufatura etc.

Alcançar o alinhamento estratégico é um processo evolutivo e dinâmico. No tocante à TI, o alinhamento estratégico requer uma mudança substancial no pensamento gerencial sobre o papel da TI na organização, assim como um entendimento da estratégia de TI e de sua importância, tanto na fundamentação como no direcionamento das decisões de estratégia de negócios (HENDERSON; VENKATRAMAN, 1993).

O uso eficaz da TI e a integração entre sua estratégia e a estratégia do negócio vão além da idéia de TI como simples ferramenta de automação de processos e produtividade. Através do alinhamento estratégico da TI, busca-se o ajuste tanto entre as estratégias de negócio e de TI, quanto entre as estruturas internas da empresa (HENDERSON; VENKATRAMAN, 1993). Atualmente, segundo Laurindo et al (2001), o caminho para o sucesso na aplicação estratégica da TI está relacionado ao alinhamento da TI com a estratégia e as características da empresa e de sua estrutura organizacional.

Em complemento à sua definição de alinhamento estratégico, Luftman (2000) defende que o alinhamento entre negócios e tecnologia da informação refere-se à aplicação de TI, de forma adequada e no momento correto, em harmonia com as estratégias, objetivos e necessidades do negócio. Assim, esse alinhamento compreende: de um lado, que TI deva estar em harmonia com os negócios e, de outro, que os negócios possam ou devam estar alinhados com TI.

Diversos modelos de alinhamento estratégico relativos a TI foram propostos, baseados em conceitos e teorias diversas e complementares, como ajuste estratégico e integração funcional (HENDERSON; VENKATRAMAN, 1993), dimensão intelectual e social (REICH; BENBASAT, 1996), teoria evolucionária e de contingência (TEO; KING, 1997), teoria da gestão do conhecimento (KEARNS; SABHERWAL, 2006) etc. Alguns autores relacionaram o alinhamento estratégico de TI com o desempenho organizacional (CHAN et al, 1997) e a efetividade de TI (CHAN et al, 1997; KEARNS; SABHERWAL, 2006). Outros propuseram formas de se medir o alinhamento estratégico de TI (LUFTMAN, 2000) e seu nível de maturidade (HIRSCHHEIM; SABHERWAL, 2001; LUFTMAN, 2000). 
Dessa forma, o objetivo deste artigo teórico é propor uma articulação entre os modelos de alinhamento estratégico de TI existentes, de modo a integrar os seus vários elementos comuns e complementares, propondo um modelo conceitual teórico.

Na sequiência, são apresentados o método de pesquisa utilizado, uma revisão dos modelos de alinhamento estratégico de TI existentes na literatura da área e a descrição do modelo conceitual proposto pelos autores. Ao final, são apresentadas as conclusões, as contribuições para a academia e a prática gerencial, bem como as limitações da pesquisa.

\section{Abordagem metodológica}

Este é um artigo de natureza teórico-exploratória. A partir de uma pesquisa exploratória sobre modelos de alinhamento estratégico de tecnologia da informação existentes, desenvolve-se uma triangulação teórica (FLICK, 1992; PATTON, 1990; SCANDURA; WILLIAMS, 2000; YIN, 2005), visando propor um novo modelo conceitual, resultante da análise crítica dos modelos estudados.

Assim, o artigo objetiva gerar um modelo heurístico a partir dos modelos conceituais estudados. Esse modelo heurístico se configura num meta-modelo conceitual de alinhamento estratégico de TI. Como afirma Winter $\left(1998\right.$, p.172-3): ${ }^{3}$

Um modelo heurístico corresponde a um grau de definição de problema que ocupa uma posição intermediária na seqüência entre uma lista longa e indiscriminada de coisas que podem importar, de um lado, e um modelo teórico de controle bastante elaborado, do outro. Dentro de um modelo heurístico, há espaço para uma ampla gama de formulações mais específicas do problema, embora também exista estrutura suficiente, fornecida pelo próprio modelo, para conduzir e dar um foco à discussão. Por outro lado, uma variedade rica de modelos heurísticos diferentes pode representar abordagens plausíveis para um problema apresentado.

Baseado nessa formulação, a metodologia apresentada é uma entre muitas que ainda podem ser utilizadas num futuro muito próximo e que representa um esforço para superar o efeito de "paralisia por análise" (ANSOFF, 1984) extremamente comum quando se lida com coisas intangíveis, levando a discussões intermináveis e não a resultados práticos. Um modelo é bom não por causa do excesso de rigor que aplica a si mesmo, medido pelo número de variáveis levadas em consideração, mas sim pelo fato de moldar e expressar adequadamente a realidade que se enfrenta. A complexidade não é necessariamente sinônimo de bons resultados, e é preciso terse alguma flexibilidade quando se lida com tópicos para os quais é necessário uma boa dose de senso crítico (JOIA, 2000).

Essa pesquisa exploratória sobre modelos de alinhamento estratégico de tecnologia da informação tem como objetivo proporcionar o aprimoramento de idéias sobre o tema da integração entre negócios e TI. Segundo Gil (2002), boa parte dos estudos exploratórios pode ser definida como pesquisas bibliográficas. Assim, a revisão sobre os modelos de alinhamento estratégico de TI, apresentada na próxima seção, foi desenvolvida através de pesquisa bibliográfica, realizada a partir de artigos publicados em revistas científicas e de teses e dissertações abordando o assunto em questão.

Com o aprofundamento no tema alinhamento estratégico de tecnologia da informação, propiciado pelo levantamento bibliográfico, passou-se a uma reflexão crítica acerca dos modelos analisados, de forma que fosse possível identificar padrões de similaridade e contradição existentes nos mesmos, para que se pudesse fundamentar um modelo conceitual de alinhamento estratégico de TI proposto pelos autores (GIL, 2002).

Para análise crítica dos modelos estudados, utilizou-se o princípio da triangulação (PATTON, 1990; YIN, 2005). No âmbito das ciências sociais, a triangulação pode ser definida como uma estratégia de pesquisa baseada na utilização de diversos métodos para investigar um mesmo fenômeno (VERGARA, 2004). A

\footnotetext{
${ }^{3}$ Tradução livre dos autores
} 
triangulação pode ser adotada como uma alternativa à obtenção de novas perspectivas relacionadas ao objeto em estudo (VERGARA, 2004).

Assim, como já dito anteriormente, neste artigo adotou-se a triangulação de teorias (PATTON, 1990; VERGARA, 2004; YIN, 2005), buscando-se analisar e comparar as diversas perspectivas teóricas existentes em cada modelo de alinhamento estratégico de TI estudado, visando à geração de um modelo conceitual abrangente, com características de frame heurístico, conforme proposto por Winter (1998).

\section{Modelos de alinhamento estratégico de TI: uma revisão}

Esta revisão se propõe a analisar as diversas proposições acerca dos modelos existentes de alinhamento estratégico de tecnologia da informação. De acordo com Stevenson (1986) e Joia (2006), modelos são aproximações da realidade desenvolvidos pelo homem. Assim, os vários modelos, aqui apresentados, devem ser vistos como tentativas baseadas em conhecimentos e métodos científicos, de retratar os meios para alcançar o alinhamento estratégico de TI nas organizações.

Esta seção procura ressaltar os pontos comuns e complementares desses vários modelos. Na seção final deste artigo, os pontos conflitantes entre os modelos apresentados são, então, comentados.

A pesquisa exploratória sobre modelos de alinhamento estratégico de tecnologia da informação tem por base o modelo de alinhamento estratégico de Henderson e Venkatraman (1993). Essa escolha se deve à sua grande aceitação no meio acadêmico e prático. O modelo de Henderson e Venkatraman (1993) é o modelo mais clássico (RIGONI, 2006) e mais discutido (REZENDE, 2002) da literatura de alinhamento estratégico da TI. Vários autores, a seguir apresentados, apoiaram-se nesse modelo para propor novas abordagens para o conceito de alinhamento estratégico de TI.

O modelo de Henderson e Venkatraman (1993) possui quatro domínios fundamentais: estratégia de negócio, estratégia de TI, infra-estrutura e processos organizacionais, e infra-estrutura e processos de TI (ver figura 1).

Na visão desses autores, a estratégia de negócios envolve: formulação (escolhas sobre abordagem competitiva, produtos e mercados) e implementação (decisões sobre a estrutura e as capacidades que irão executar as escolhas de produtos e mercados). Da mesma forma, a estratégia de TI deve envolver: escolhas sobre os tipos de tecnologias da informação a serem empregadas e seus meios de utilização e de aquisição (formulação), além de decisões sobre como a infra-estrutura de TI deve ser configurada e gerenciada (implementação).

Henderson e Venkatraman (1993) afirmam que o alinhamento estratégico de TI é baseado em: (1) ajuste estratégico entre o posicionamento da organização e de TI no mercado (ambiente externo) e a infra-estrutura administrativa adequada para dar sustentação a tal posicionamento (ambiente interno), e (2) integração funcional entre os domínios de negócio e de TI, tanto no nível estratégico quanto no nível de infra-estrutura e processos. 


\section{Figura 1}

\section{Modelo de alinhamento estratégico de TI de Henderson e Venkatraman}

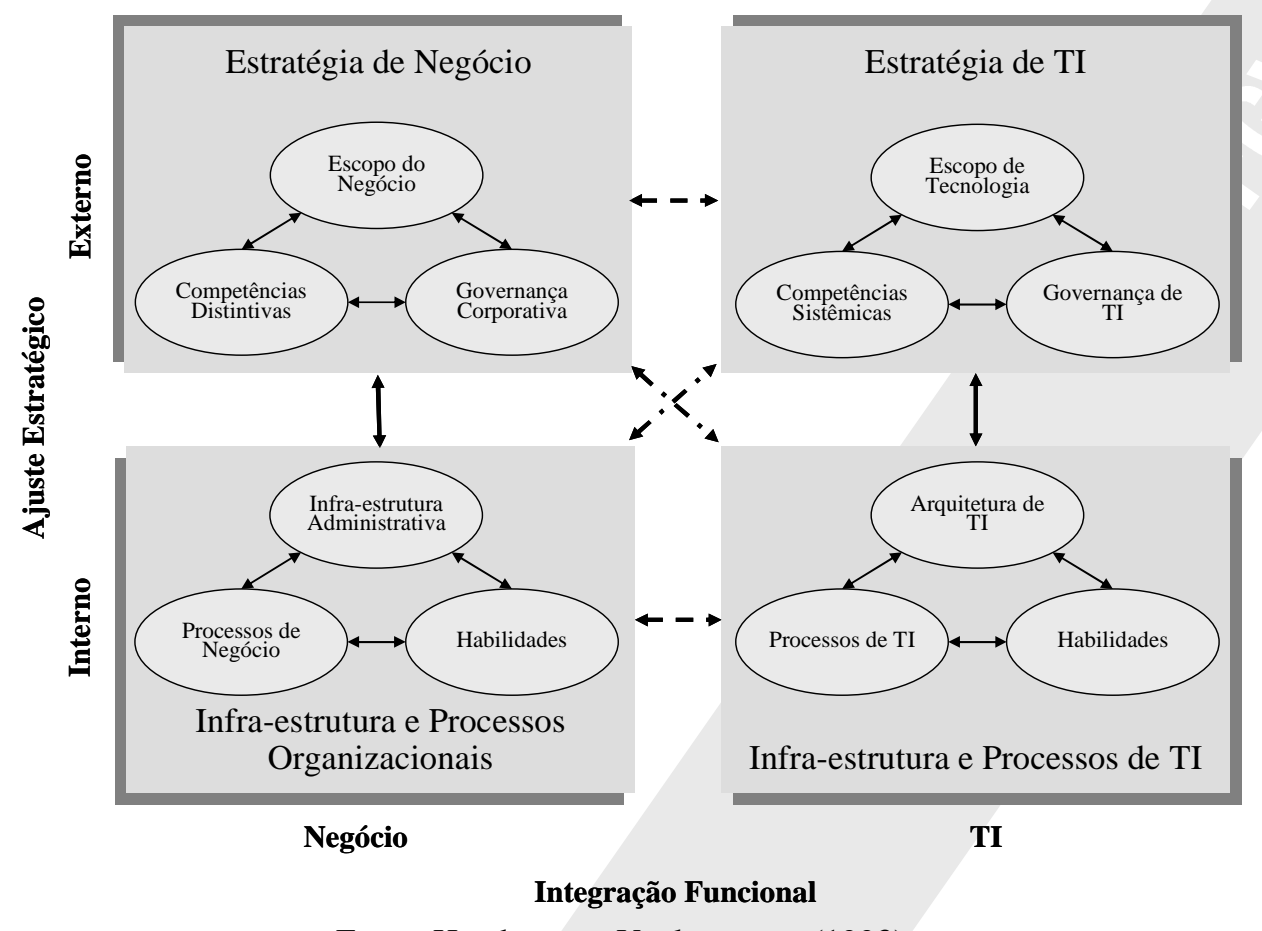

Fonte: Henderson e Venkatraman (1993).

Os autores sustentam que o alinhamento estratégico de TI não é um evento, mas um processo contínuo de adaptação e mudança. Consideram que, para alcançá-lo, é necessária uma substancial mudança no pensamento gerencial sobre o papel da TI na organização, assim como um entendimento da estratégia de TI e de sua importância, tanto na fundamentação, como no direcionamento das decisões de estratégia de negócios.

Henderson e Venkatraman (1993) não associam diretamente o alinhamento estratégico de TI ao desempenho organizacional, mas afirmam que a falta de alinhamento é uma das causas dos questionamentos sobre os resultados dos investimentos feitos em TI.

O segundo modelo abordado é o de Reich e Benbasat (1996). Eles apresentam um framework de integração entre negócios e TI, definido em termos da dimensão intelectual e da dimensão social (quadro 1).

Os autores fazem uma distinção entre as causas (fatores que influenciam o alinhamento estratégico de TI) e o efeito (o alinhamento estratégico de TI, per si). Segundo os autores, os processos organizacionais são as causas potenciais de alinhamento entre negócios e TI.

Reich e Benbasat (1996) definem alinhamento estratégico entre negócios e TI como o grau com o qual a missão, objetivos e planos de TI suportam e são suportados pela missão, objetivos e planos de negócios. 


\section{Quadro 1 \\ Modelo de Reich e Benbasat}

\begin{tabular}{lll}
\hline $\begin{array}{l}\text { Dimensão de } \\
\text { Integração }\end{array}$ & $\begin{array}{l}\text { FATORES } \\
\text { Potenciais de Influência na } \\
\text { Integração (Causas) }\end{array}$ & $\begin{array}{l}\text { INTEGRAÇÃO } \\
\text { (Efeito) }\end{array}$ \\
\hline Dimensão Intelectual & $\begin{array}{l}\text { I. Metodologias para formulação da } \\
\text { missão, objetivos e planos, de } \\
\text { Negócios e de TI, além do } \\
\text { detalhamento das atividades de } \\
\text { planejamento. }\end{array}$ & $\begin{array}{l}\text { II. Grau de consistência interna e } \\
\text { validade externa da missão, objetivos e } \\
\text { planos, de Negócios e de TI. }\end{array}$ \\
\hline Dimensão Social & $\begin{array}{l}\text { III. Escolhas dos participantes, } \\
\text { momento, processos de decisão e de } \\
\text { comunicação usados na formulação } \\
\text { da missão, objetivos e planos, de } \\
\text { Negócios e de TI. }\end{array}$ & $\begin{array}{l}\text { IV. Nível de entendimento da missão, pelos executivos de Negócios e de } \\
\text { objetivos e planos, de Negócios e de } \\
\text { TI; }\end{array}$ \\
\hline
\end{tabular}

Fonte: Reich e Benbasat (1996).

O conceito novo que Reich e Benbasat (1996) apresentam é a distinção entre as dimensões intelectuais (metodologias, técnicas e dados utilizados na formulação da estratégia) e sociais (escolha dos participantes, grau de envolvimento, métodos de comunicação e tomada de decisão) associadas ao processo de planejamento estratégico.

A dimensão intelectual entre negócios e TI diz respeito ao fato dos objetivos de negócio e de TI serem consistentes (por estarem integrados internamente) e válidos (em relação ao ambiente externo). Tal dimensão é similar aos conceitos de ajuste estratégico e integração funcional de Henderson e Venkatraman (1993). Já a dimensão social da integração entre negócios e TI é o estado em que os executivos de negócio e de TI, mutuamente, entendem e estão comprometidos com a missão, objetivos e planos das áreas recíprocas. Essa última dimensão relaciona-se, principalmente, com os conceitos de formulação e implementação (ver figura 1) de Henderson e Venkatraman (1993).

Com relação à necessidade de mudança no pensamento gerencial sobre o papel da TI na organização, Reich e Benbasat (1996) - no estudo de caso de uma seguradora canadense - identificaram alguns executivos que admitiam não terem "idéia do que a TI poderia agregar aos seus negócios e [que por isso] confiavam no pessoal de TI para a elaboração os planos para aplicação da TI" (REICH; BENBASAT, 1996, p.69, tradução dos autores).

Reich e Benbasat (1996) também identificaram diferenças na percepção e no entendimento dos executivos de negócio e de TI a respeito do alinhamento estratégico de TI nas organizações.

As teorias evolucionária e de contingência são as contribuições de Teo e King (1997) para o campo do alinhamento estratégico de TI (figura 2). Segundo esses autores, existe um padrão evolutivo na integração entre negócios e TI que segue quatro etapas:

- Integração Administrativa: planos separados de negócios e tecnologia da informação; esta é pouco empregada para dar suporte aos negócios;

- Integração Seqüencial: planos de negócio direcionam os planos de TI, na qual esses negócios se assentam;

- Integração Recíproca: planos de negócios e de TI estão relacionados; esta dá suporte aos negócios e os influencia e

- Integração Plena: planos de negócios e de TI são desenvolvidos de forma simultânea e integrados; a TI dá suporte aos negócios, influenciando-os. 
Em seus estudos, Teo e King (1997) identificaram que: (1) é pouco comum que se pule uma etapa ou que ocorra uma evolução reversa; (2) as organizações não iniciam o processo de alinhamento estratégico, necessariamente, pela primeira etapa; e (3) o tempo associado a cada etapa decresce, à medida que a organização evolui na integração entre negócios e TI.

Figura 2

\section{Modelo de Teo e King}

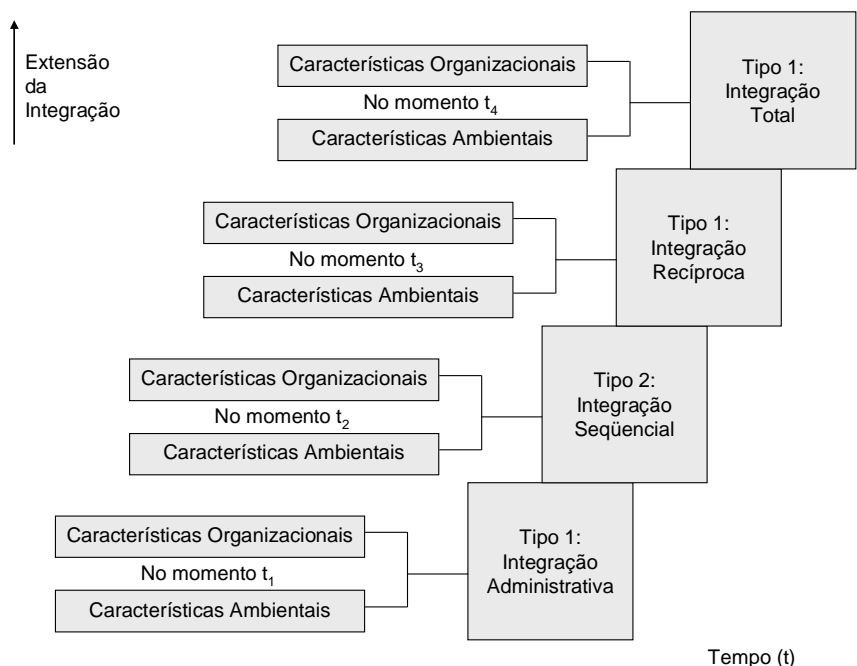

Fonte: Teo e King (1997).

Os autores analisaram, também, a influência das características organizacionais e ambientais na extensão da integração entre Negócios e TI e identificaram que o conhecimento do executivo de TI sobre os negócios de sua organização é o fator mais significativo para o alinhamento estratégico de TI.

O quarto modelo discutido é o de Chan et al. (1997), que associa diretamente o alinhamento estratégico de TI (representado pelo ajuste entre as orientações estratégicas de Negócios e de TI) com a Efetividade da TI e o Desempenho Organizacional (Figura 3).

Figura 3

Modelo de Chan

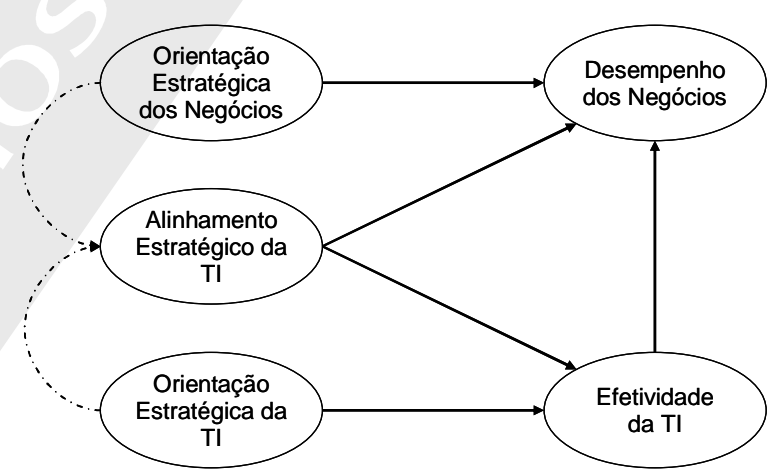

Fonte: Chan et al (1997). 
Chan et al (1997) argumentam que criar a estratégia de TI é apenas o primeiro passo para o alinhamento estratégico de TI e que o segundo passo, a sua implementação, é igualmente crítico. Esses autores procuram explicitar a conexão entre as estratégias realizadas (em contraste com as estratégias planejadas) e o alinhamento estratégico e o desempenho, tanto no nível de TI quanto no de negócio. Eles mostram que nas organizações de melhor desempenho ocorre alinhamento entre as estratégias de negócios e de TI.

Seus estudos mostram que o alinhamento estratégico de TI é melhor indicador do desempenho organizacional e da efetividade da TI do que a orientação estratégica de negócios e a orientação estratégica de TI. A orientação estratégica de TI, por si só, não é um bom indicador da efetividade da TI; ou seja, sem estar alinhada com os negócios, a TI não atende à organização. Além disso, mostram que a efetividade da TI contribui para o desempenho organizacional; isto é, os sistemas de informação contribuem para os resultados organizacionais. Este estudo avança nas respostas às questões sobre os resultados advindos dos investimentos em TI, abordadas na introdução deste artigo.

Chan et al (1997) acrescentam ainda que a formulação da estratégia de TI deve receber cuidadosa atenção e envolver a participação da administração sênior da organização, pois as decisões tomadas quanto a direção, alocação de recursos e uso da TI têm conseqüências importantes para o desempenho e os resultados da organização.

O próximo modelo surge da necessidade de se medir a adequação entre negócios e TI. Luftman (2000) propõe um modelo para avaliar o grau de maturidade do alinhamento estratégico entre negócios e TI (figura 4). $\mathrm{O}$ grau de maturidade cresce com o aumento da capacidade de TI e das demais áreas funcionais de desenvolverem e adaptarem mutuamente suas estratégias. Seu estudo é fortemente baseado no modelo de Henderson e Venkatraman (1993).

Figura 4

Modelo de Luftman (2000)

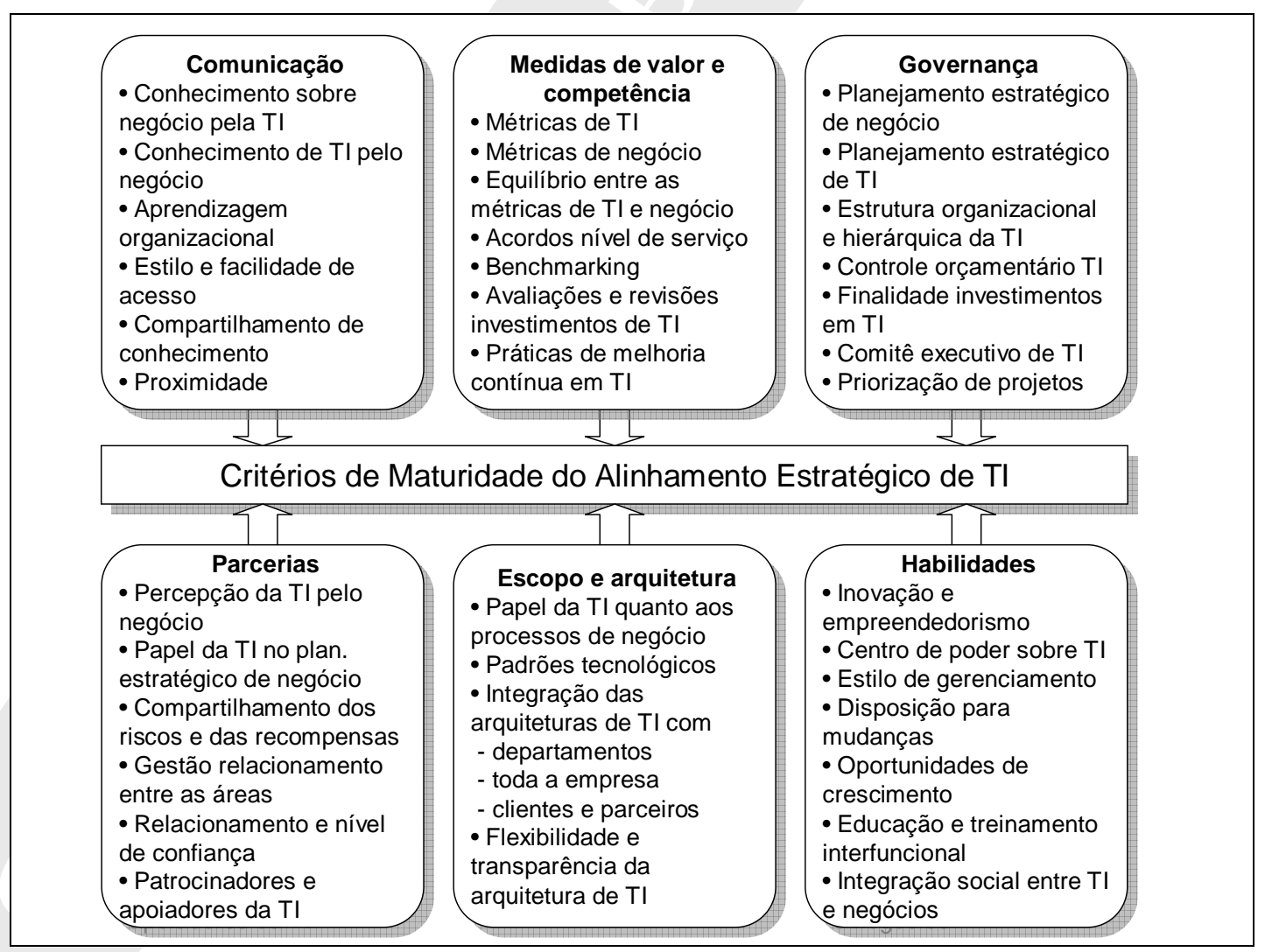

Fonte: Luftman (2000). 
Luftman (2000) defende que o alinhamento entre negócios e tecnologia da informação refere-se à aplicação de TI, de forma adequada e no momento correto, em harmonia com as estratégias, objetivos e necessidades do negócio. Assim, esse alinhamento compreende, de um lado, que a TI deva estar em harmonia com os negócios e, de outro, que os negócios possam (ou devam) estar alinhados com a TI.

Os seis critérios e práticas de alinhamento negócios/TI propostos pelo modelo de Luftman (2000) são: comunicação, medidas de valor e competência, governança, parceria, escopo e arquitetura, e habilidades.

Luftman (2000), como Reich e Benbasat (1996), reconhece a possibilidade de diferenças de percepção entre os executivos de negócio e de TI sobre o alinhamento estratégico. Em seu modelo, Luftman (2000) recomenda que o trabalho de avaliação da maturidade deva ser feito por uma equipe que inclua executivos de negócio e de TI. O autor ressalta que o consenso alcançado - por meio das discussões em grupo - sobre o nível de maturidade do alinhamento estratégico de TI da organização, é extremamente importante para o entendimento dos problemas e oportunidades que precisam ser endereçados para melhorar a sinergia entre negócios e tecnologia da informação.

A avaliação de maturidade do alinhamento estratégico de TI fornece um meio para se avaliar onde a organização está, e para onde ela deve caminhar, de forma a obter e dar sustentação ao alinhamento entre negócios e TI (LUFTMAN, 2000).

O sexto modelo examinado é o de Hirschheim e Sabherwal (2001). Os autores apresentam um modelo de perfis de alinhamento. Apesar de reconhecerem que o alinhamento estratégico de TI é uma via de mão dupla - a estratégia de negócio influencia a estratégia de TI e vice-versa (ajuste estratégico) -, o modelo de Hirschheim e Sabherwal (2001) é extremamente prescritivo. Para obter o alinhamento estratégico de TI, tanto a estratégia de negócios, quanto a estratégia de TI, devem seguir o perfil de alinhamento que o modelo prescreve (quadro 2).

Quadro 2

Modelo de Hirschheim e Sabherwal

\begin{tabular}{|c|c|c|c|}
\hline Perfil de Alinhamento & $\begin{array}{l}\text { Infusion: } \\
\text { Alinhamento através da } \\
\text { Liderança dos Negócios }\end{array}$ & $\begin{array}{l}\text { Alliance: } \\
\text { Alinhamento através de } \\
\text { Parcerias }\end{array}$ & $\begin{array}{l}\text { Utility: } \\
\text { Alinhamento através de } \\
\text { Baixos Custos }\end{array}$ \\
\hline Estratégia de Negócio & $\begin{array}{l}\text { Busca de novas } \\
\text { oportunidades }\end{array}$ & Análise & Defesa \\
\hline $\begin{array}{l}\text { Estratégia de TI } \\
\text { - Papel da TI } \\
\text { - Sourcing da TI } \\
\text { - Estrutura da TI }\end{array}$ & $\begin{array}{l}\text { Oportunista } \\
\text { Interno } \\
\text { Descentralizada }\end{array}$ & $\begin{array}{l}\text { Abrangente } \\
\text { Interno/Externo } \\
\text { Compartilhada }\end{array}$ & $\begin{array}{l}\text { Eficiente } \\
\text { Externo } \\
\text { Centralizada }\end{array}$ \\
\hline
\end{tabular}

Fonte: Hirschheim e Sabherwal (2001).

Na visão dos autores, a estratégia de TI se divide em três dimensões:

- papel da TI (como esta é vista pela gerência sênior da organização);

- sourcing da TI (como os produtos e serviços de TI são adquiridos); e

- estrutura da TI (como a TI é organizada e como suas decisões são tomadas).

Assim, quando a organização necessita alterar sua estratégia de negócios ou de TI, deverá modificar todos os componentes do perfil de alinhamento estratégico desta. 
Segundo os autores, o desempenho organizacional está relacionado à capacidade da organização de conseguir as estruturas e capacidades apropriadas para executar suas decisões estratégicas (integração funcional).

Ao conceito de processo contínuo de Henderson e Venkatraman (1993), Hirschheim e Sabherwal (2001) acrescentam que o alinhamento estratégico de TI surge em meio a um processo incremental de implementação e aprendizado, ressaltando que durante processos de mudança nas estratégias de negócio ou de TI poderão ocorrer momentos de menor alinhamento estratégico de TI e, possivelmente, redução no desempenho dos negócios e de TI.

Sétimo modelo analisado (figura 5), o modelo de Kearns e Sabherwal (2006) aproxima a teoria da gestão do conhecimento do tema alinhamento estratégico. Para tal, enfatiza a participação de gerentes de negócio no planejamento estratégico de TI e a participação de gerentes de TI no planejamento estratégico de negócio.

\section{Figura 5}

\section{Modelo de Kearns e Sabherwal}

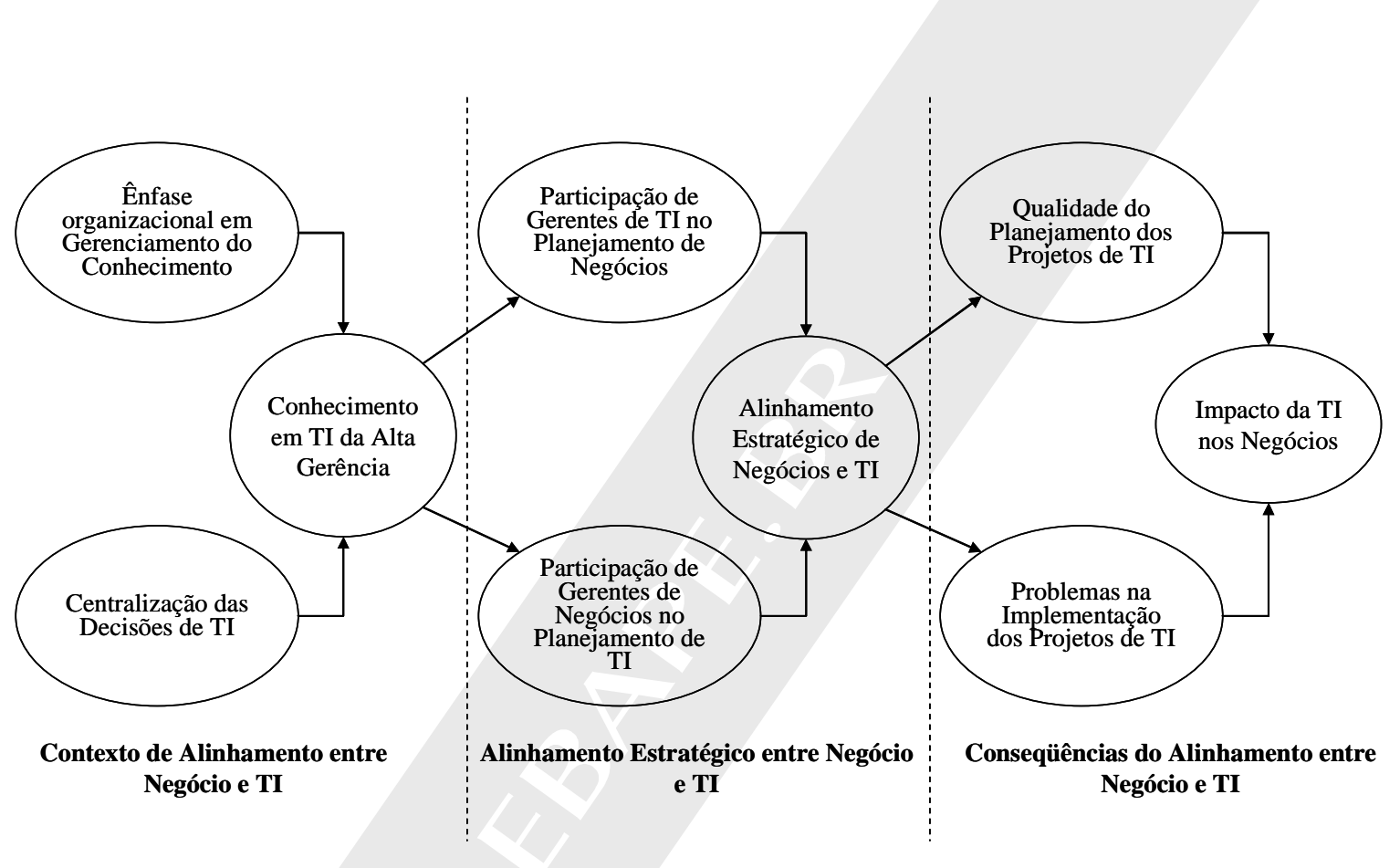

Fonte: Kearns e Sabherwal (2006).

De acordo com o modelo de Kearns e Sabherwal (2006), a ênfase organizacional na gestão do conhecimento e a centralização das decisões de TI influenciam no conhecimento de TI pela gerência sênior, o que facilita a participação de gerentes de negócios no planejamento estratégico de TI e a participação de gerentes de TI no planejamento estratégico de negócios. Esses dois comportamentos de planejamento influenciam o alinhamento estratégico de negócios e TI.

Os autores incluem o projeto de TI como mediador da relação entre alinhamento estratégico de TI e o efeito da tecnologia da informação sobre os negócios. Assim, a qualidade do plano de projeto de TI e a quantidade de problemas na sua implementação medeiam a relação entre alinhamento estratégico de TI e o efeito da tecnologia da informação sobre os negócios. O projeto de TI é o meio pelo qual o alinhamento estratégico de TI converte-se em sistemas de informação e, conseqüentemente, em resultados para o Negócio. Junto com Chan et al (1997), o trabalho de Kearns e Sabherwal (2006) também contribui para a questão dos resultados dos investimentos em tecnologia da informação. 
Ao contrário de Teo e King (1997), que ressaltaram a importância do conhecimento do executivo de TI sobre os negócios de sua organização, Kearns e Sabherwal (2006) identificaram que o conhecimento de TI pelos executivos de Negócio contribui mais para o alinhamento estratégico de TI do que o conhecimento do executivo de TI sobre os negócios da organização.

O último modelo apresentado é brasileiro. Brodbeck e Hoppen (2003) propõem um modelo de promoção do alinhamento estratégico de TI, estendido à etapa de execução da estratégia (figura 6). Trata-se de uma extensão do modelo original de Henderson e Venkatraman (1993).

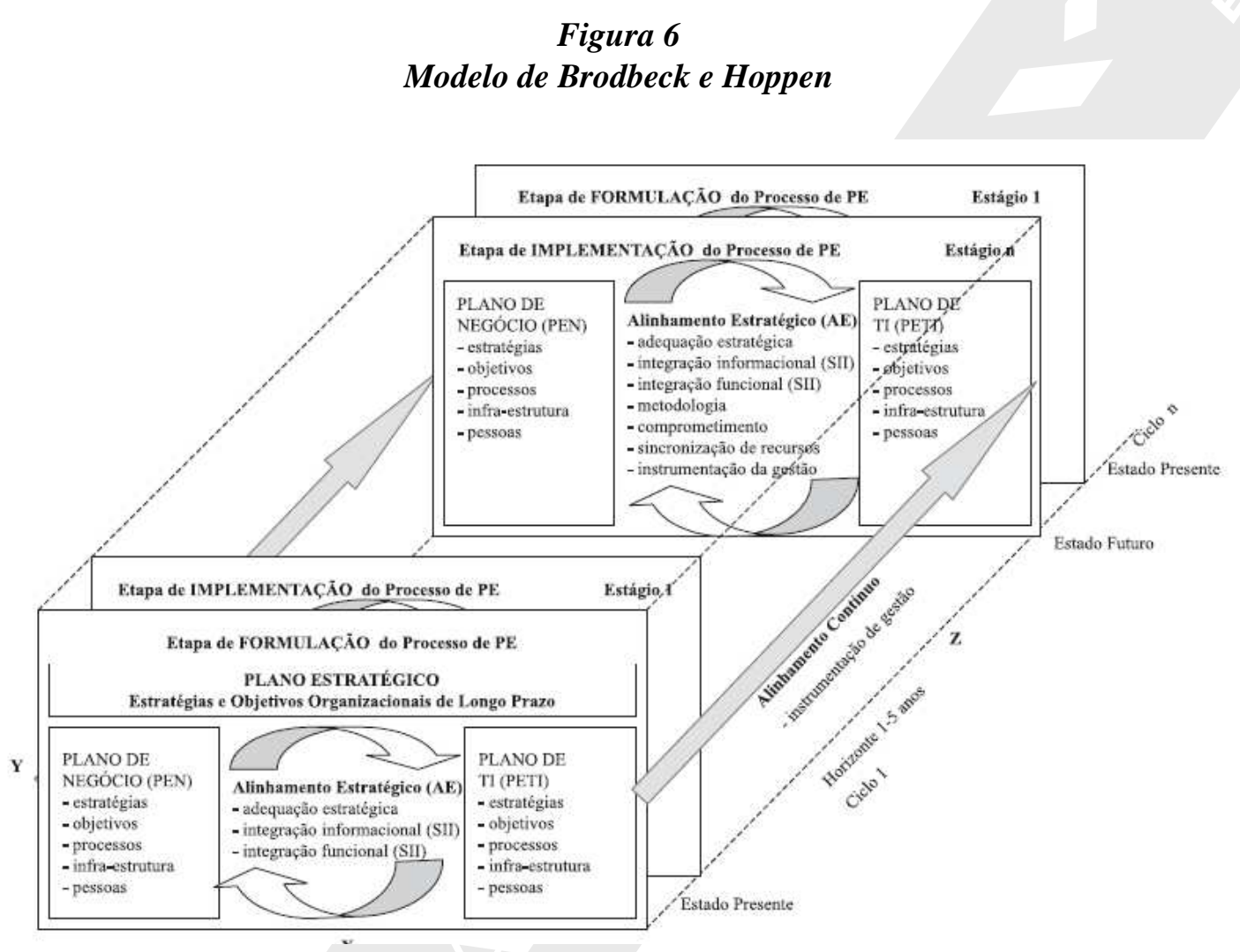

Fonte: Brodbeck e Hoppen (2003).

O modelo adota uma visão espacial, contendo um plano de frente que representa a promoção do alinhamento entre negócios e TI durante a etapa de formulação do planejamento estratégico. Os vários planos de fundo representam a promoção do alinhamento contínuo durante os diferentes estágios da execução da estratégia (implementação).

De acordo com Brodbeck e Hoppen (2003), o modelo pode ser interpretado como um cubo formado pelo ciclo de cada processo de planejamento - representando a continuidade da promoção do alinhamento -, expresso pelo:

- alinhamento circular (no plano) entre objetivos e estratégias de negócio e de TI, indicando que ambos podem redirecionar o alinhamento, a qualquer instante; $\mathrm{e}$

- alinhamento cíclico e crescente no tempo e espaço, indicando o movimento dos itens planejados do estado presente para o estado futuro. 
Em suas pesquisas, os autores identificaram que o alinhamento sempre ocorre pelo caráter subjetivo da gestão dos $\mathrm{CEOs}^{4}$ e dos CIOs, ${ }^{5}-$ muitas vezes informal e instintiva -, ao promover ajustes entre os negócios e TI.

Esta seção termina com um resumo dos modelos revisados anteriormente (quadro 3). O ponto de partida para sua montagem foram os principais conceitos do modelo de Henderson e Venkatraman (1993), a saber:

- formulação da estratégia de TI: escolhas sobre os tipos de tecnologias da informação a serem empregadas e seus meios de utilização e de aquisição;

- implementação da estratégia de TI: decisões sobre como a infra-estrutura de TI deve ser configurada e gerenciada;

- ajuste estratégico: alinhamento entre o posicionamento da organização e de TI no mercado (ambiente externo) e a infra-estrutura administrativa adequada para garantir tal posicionamento (ambiente interno);

- integração funcional: alinhamento entre os domínios de negócio e de TI, tanto no nível estratégico, quanto no nível de infra-estrutura e processos;

- processo contínuo: entendimento de que o alinhamento estratégico de TI não é um evento, mas um processo contínuo de adaptação e mudança;

- mudança no pensamento gerencial: necessidade da gerência sênior reconhecer o potencial de TI, tanto para dar sustentação, quanto no direcionamento das decisões de estratégia de negócios.

$\mathrm{O}$ quadro 3 mostra os pontos em comum entre cada modelo apresentado e o modelo de Henderson e Venkatraman (1993) (assinalados com um "X"), assim como as novas contribuições, trazidas pelos autores pesquisados, a esse modelo (assinaladas com um “+”). Assim, é possível identificar a influência do trabalho de Henderson e Venkatraman (1993) na área de alinhamento estratégico de TI, destacando como os demais autores utilizaram os conceitos propostos por eles. O quadro também permite verificar que os demais autores em consonância com o objetivo da pesquisa científica de aprimoramento constante do conhecimento trouxeram novas idéias para o campo do alinhamento estratégico de TI, tais como:

- Reich e Benbasat (1996) ressaltaram a distinção entre as dimensões intelectuais e sociais no processo de planejamento estratégico e as diferenças de percepção dos executivos de negócios e de TI no alinhamento estratégico de TI em suas organizações;

- Teo e King (1997) juntaram as teorias evolucionária e de contingência para propor um padrão de evolução da integração entre negócios e TI. Identificaram, também, a importância do conhecimento do executivo de TI nos negócios de sua organização para o alinhamento estratégico de TI;

- Chan et al (1997) associaram o alinhamento estratégico de TI com a efetividade da TI e o desempenho organizacional. Mostraram, também, que a efetividade da TI contribui para o desempenho organizacional, acrescentando que a formulação da estratégia de TI deve receber a atenção da administração sênior da organização;

- Luftman (2000) propôs um modelo para avaliar o grau de maturidade do alinhamento estratégico entre negócios e TI e, como em Reich e Benbasat (1996), reconheceu a possibilidade de diferenças de percepção entre os executivos de negócio e de TI quanto ao alinhamento estratégico de TI;

- Hirschheim e Sabherwal (2001) apresentam um modelo de perfis de alinhamento, acrescentando que o alinhamento estratégico de TI é um processo incremental de implementação e aprendizado.

- Kearns e Sabherwal (2006) utilizaram a teoria da gestão do conhecimento para mostrar a importância do conhecimento de tecnologia da informação pela gerência sênior. Também incluíram o projeto de TI como mediador na relação entre alinhamento estratégico de TI e o efeito de TI nos negócios. Além

\footnotetext{
${ }^{4}$ CEO (chief executive officer): gestor de negócios é o executivo ou dirigente da organização.

${ }^{5} \mathrm{CIO}$ (chief information officer): gestor de TI é o executivo responsável pela TI na organização.
} 
disso, ao contrário de Teo e King (1997), identificaram que o conhecimento de tecnologia da informação pelos executivos de negócio contribui mais para o alinhamento estratégico de TI do que o conhecimento do executivo de TI sobre os negócios da organização;

- Brodbeck e Hoppen (2003) propuseram um modelo de promoção do alinhamento estratégico entre os planos estratégicos de negócio e de TI, estendido para a etapa de implementação dessas estratégias.

Quadro 3

Consolidação dos modelos estudados

\begin{tabular}{|c|c|c|c|c|c|c|c|c|}
\hline Conceitos & 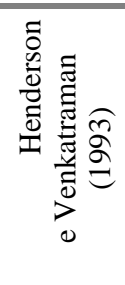 & 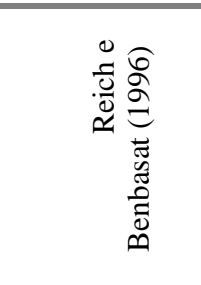 & 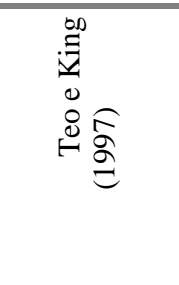 & 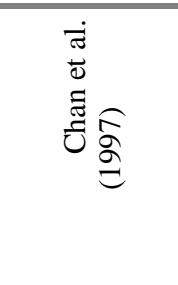 & 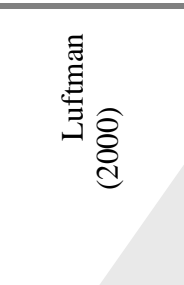 & 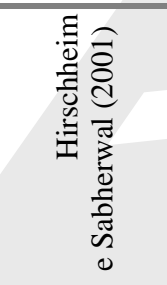 & 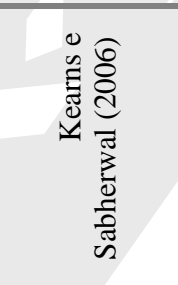 & 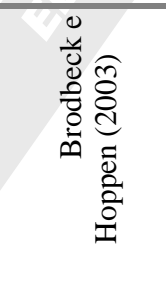 \\
\hline $\begin{array}{l}\text { Formulaçã } \\
\text { o e Implementação }\end{array}$ & & $\begin{array}{c}\text { X } \\
\text { Dimensão } \\
\text { Social }\end{array}$ & 更 & $\begin{array}{c}\text { X } \\
\text { (+) Atenção } \\
\text { e } \\
\text { Participação } \\
\text { da Gerência } \\
\text { Sênior na } \\
\text { Estratégia de } \\
\text { TI }\end{array}$ & $X$ & & $\begin{array}{c}\quad \quad \text { X } \\
\quad(+) \\
\text { Participação } \\
\text { recíproca de } \\
\text { TI e Negócio } \\
\text { nas } \\
\text { Estratégias }\end{array}$ & $\mathrm{X}$ \\
\hline $\begin{array}{l}\text { Ajuste } \\
\text { Estratégico }\end{array}$ & & $\begin{array}{c}{ }_{(+)} \\
\text {Dimensão } \\
\text { Intelectual }\end{array}$ & $X$ & 0 & & $\begin{array}{r}\text { X } \\
\text { (+) Modelo } \\
\text { Prescritivo }\end{array}$ & & X \\
\hline $\begin{array}{l}\text { Integração } \\
\text { Funcional }\end{array}$ & & $\begin{array}{c}\text { X } \\
\text { Dimensão } \\
\text { Intelectual }\end{array}$ & $\mathrm{X}$ & $\mathrm{X}$ & $X$ & $X$ & & $X$ \\
\hline $\begin{array}{l}\text { Processo } \\
\text { Contínuo }\end{array}$ & & X & $\mathrm{X}$ & & $\mathrm{X}$ & $\begin{array}{l}\text { X } \\
\text { (+) Processo } \\
\text { incremental } \\
\text { de } \\
\text { implementa- } \\
\text { ção e } \\
\text { aprendizado } \\
\end{array}$ & & $\mathrm{X}$ \\
\hline $\begin{array}{l}\text { Mudança } \\
\text { no Pensamento } \\
\text { Gerencial }\end{array}$ & & $\mathrm{X}$ & $\begin{array}{c}\text { X } \\
\text { (+) Conheci- } \\
\text { mento de } \\
\text { Negócio pela } \\
\text { Gerência de } \\
\text { TI }\end{array}$ & 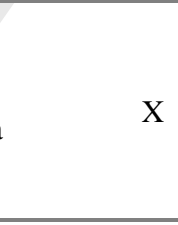 & $X$ & & $\begin{array}{c}\text { X } \\
\text { (+) Conheci- } \\
\text { mento de TI } \\
\text { pela } \\
\text { Gerência } \\
\text { Sênior }\end{array}$ & X \\
\hline $\begin{array}{l}\quad \text { Novos } \\
\text { Conceitos ao } \\
\text { Modelo de } \\
\text { Henderson e } \\
\text { Venkatraman } \\
\text { (1993) }\end{array}$ & & $\begin{array}{c}(+) \\
\text { Diferença de } \\
\text { Percepção } \\
\text { entre } \\
\text { Executivos } \\
\text { de Negócio e } \\
\text { TI }\end{array}$ & $\begin{array}{c}\text { Teoria } \\
\text { Evolucio- } \\
\text { nária e de } \\
\text { Contingência } \\
\end{array}$ & $\begin{array}{c}\text { (+) } \\
\text { Relação AE } \\
\text { com } \\
\text { Desempenho } \\
\text { Organiza- } \\
\text { cional e } \\
\text { Efetividade } \\
\text { da TI } \\
(+) \\
\text { Efetividade } \\
\text { da TI } \\
\text { contribui } \\
\text { para } \\
\text { Desempenho } \\
\text { Organiza- } \\
\text { cional }\end{array}$ & $\begin{array}{l}\text { (+) } \\
\text { Medição do } \\
\text { Grau de } \\
\text { Maturidade } \\
\text { do AE } \\
\text { (+) Diferença } \\
\text { de Percepção } \\
\text { entre } \\
\text { Executivo de } \\
\text { Negócio e TI }\end{array}$ & & $\begin{array}{c}\quad(+) \\
\text { Teoria da } \\
\text { Gestão do } \\
\text { Conheci- } \\
\text { mento } \\
\text { (+) Projeto } \\
\text { de TI como } \\
\text { mediador } \\
\text { entre AE e o } \\
\text { Desempenho } \\
\text { Organiza- } \\
\text { cional }\end{array}$ & $\begin{array}{c}\text { Expande o } \\
\text { AE para a } \\
\text { execução da } \\
\text { Estratégia }\end{array}$ \\
\hline
\end{tabular}

Fonte: elaborado pelos autores. 
Sigla e sinais: $\mathrm{AE}=$ alinhamento estratégico de $\mathrm{TI} ; \mathrm{X}=$ ponto em comum entre os modelos; $(+)=$ contribuição dada ao modelo de Henderson e Venkatraman (1993).

\section{Articulando modelos de alinhamento estratégico de TI: uma proposição}

Os vários modelos de alinhamento estratégico revisados na seção anterior são tentativas de representar a realidade (STEVENSON, 1986). Os mesmos fornecem, essencialmente, várias avaliações do mesmo fenômeno (YIN, 2005), e sua triangulação e concatenação permitem gerar um novo modelo (VERGARA, 2004). Esperase que esse novo modelo seja válido e que represente a mesma realidade de forma mais fidedigna do que a conseguida pelos modelos precedentes, já que se trata de uma evolução incremental no conhecimento acumulado na área de alinhamento estratégico de TI.

Segundo Winter (1998), um modelo é bom, não por causa do excessivo rigor que aplica a si mesmo - medido pelo número de variáveis levadas em consideração -, mas, sim, pelo fato de moldar e expressar adequadamente a realidade que enfrenta. $\mathrm{O}$ modelo conceitual proposto foi desenvolvido com esse objetivo, apesar de sua validação não fazer parte do escopo deste artigo. A figura 7 ilustra o modelo aqui proposto:

\section{Figura 7 \\ Modelo conceitual proposto}

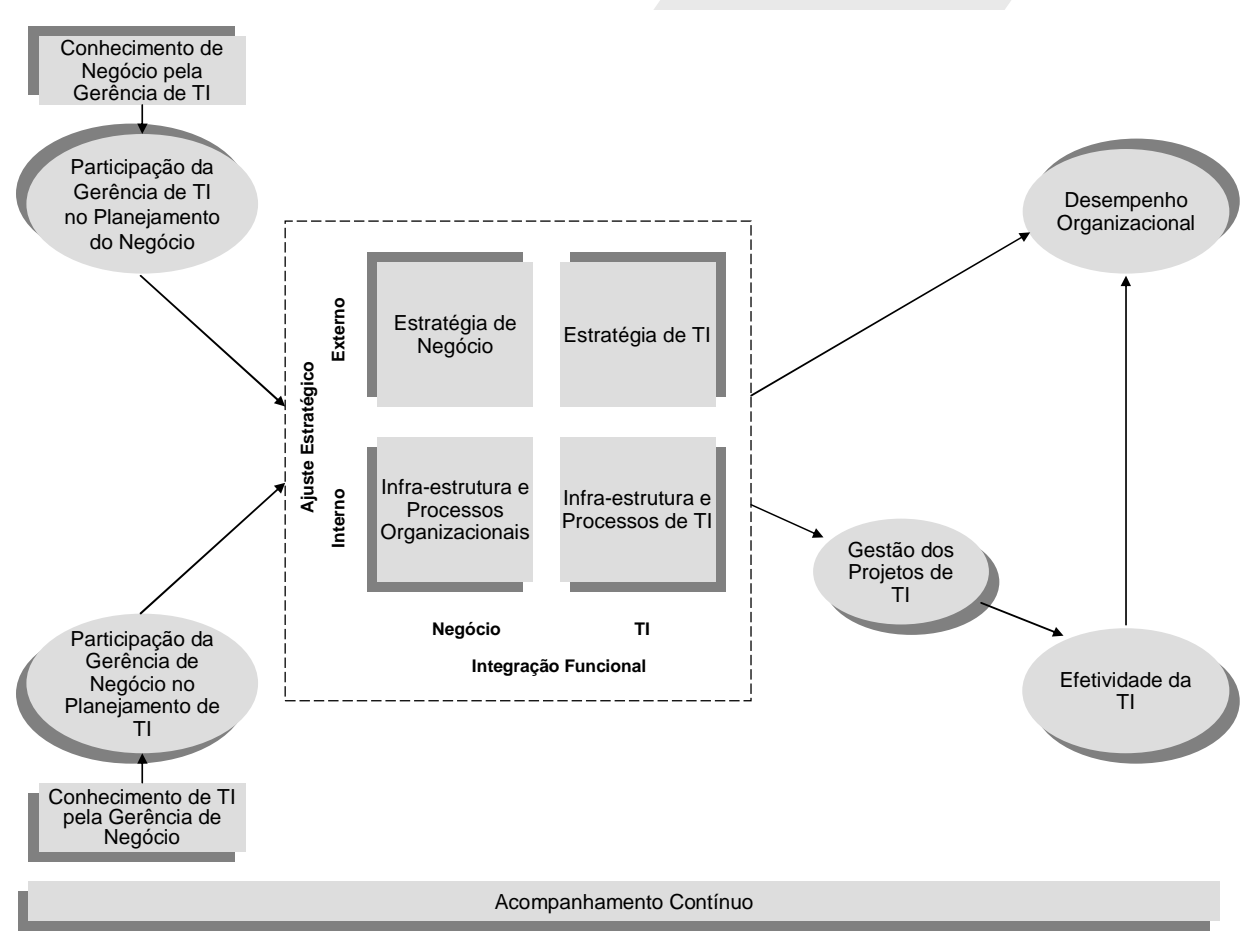

Fonte: elaborado pelos autores.

O modelo conceitual proposto é abrangente. Apesar de nenhum outro modelo ou argumento teórico poder ser citado para respaldar todas as suas premissas e hipóteses (CHAN et al, 1997), os modelos revisados anteriormente fundamentam sua elaboração, conforme demonstrado a seguir.

As idéias do trabalho de Henderson e Venkatraman (1993) de que a estratégia envolve formulação e implementação, de que o alinhamento estratégico de TI é baseado no ajuste estratégico e na integração funcional, que é um processo contínuo e que requer uma mudança no pensamento gerencial sobre o papel da TI 
formam o núcleo, a parte central, do modelo proposto. Como mostra o quadro 3 (seção anterior) esses conceitos estão presentes na maioria dos modelos estudados.

O lado esquerdo do modelo proposto (figura 7) explicita dois fatores que influenciam diretamente o alinhamento estratégico de TI: a necessidade de participação da gerência de TI no planejamento de negócio e a necessidade de participação da gerência de negócio no planejamento de TI.

A dimensão social do processo de planejamento estratégico (REICH; BENBASAT, 1996), a atenção e participação da administração sênior da organização no processo de formulação de estratégia (CHAN et al, 1997) e a teoria da gestão do conhecimento (KEARNS; SABHERWAL, 2006) justificam a participação de executivos de negócio e de TI, reciprocamente, nos processos de formulação das estratégias de negócio e de TI.

O modelo faz, também, ainda em seu lado esquerdo, uma recomendação quanto às habilidades requeridas dos profissionais de negócio e de TI, que irão participar e, efetivamente, contribuir para que a organização alcance o alinhamento estratégico de TI. Os profissionais de negócio precisam entender a capacidade, aplicabilidade e potencial da TI e reconhecer a importância de envolvê-la, desde o início, no processo de planejamento estratégico da organização. Esse conhecimento de TI pela gerência de negócio foi ressaltado no modelo de Kearns e Sabherwal (2006) e incluído no modelo proposto. De forma similar, os profissionais de TI precisam ter conhecimentos sobre os mercados e produtos de sua organização. A necessidade de conhecimento de negócio pela gerência de TI foi demonstrada no modelo de Teo e King (1997), que argumentam que tal conhecimento facilita o processo de convencimento da alta gerência sobre a importância da TI para a organização alcançar seus objetivos de negócio.

O lado direito do modelo proposto (figura 7) responde aos questionamentos sobre os resultados alcançados pelos investimentos em tecnologia da informação realizados pelas organizações. Sua fundamentação teórica baseia-se na relação do alinhamento estratégico de TI com o desempenho organizacional e com a eficácia da TI (CHAN et al., 1997), na relação da eficácia da TI com o desempenho organizacional (CHAN et al, 1997) e na gestão dos projetos de TI como mediadora da relação entre alinhamento estratégico e o impacto da TI nos negócios (KEARNS; SABHERWAL, 2006).

O modelo conceitual propõe que a qualidade do plano de projeto de TI e a quantidade de problemas na sua implementação (KEARNS; SABHERWAL, 2006) - representadas pela gestão dos projetos de TI - irão mediar a relação entre o alinhamento estratégico de TI e a efetividade de TI. Esta, por sua vez, irá influenciar o desempenho organizacional (CHAN et al, 1997). Da mesma forma, o alinhamento estratégico de TI (CHAN et al, 1997) também irá influenciá-lo.

Por fim, para destacar os aspectos de continuidade do processo de alinhamento estratégico ressaltado por vários autores - especialmente, por Brodbeck e Hoppen (2003) -, o modelo proposto apresenta em sua parte inferior, como uma base de sustentação, a função acompanhamento contínuo. Para alcançar o alinhamento estratégico de TI, todos os envolvidos devem entender que este se trata de um processo incremental de implementação e aprendizado (HIRSCHHEIM; SABHERWAL, 2001). Isto é, poderão ocorrer momentos de maior ou menor alinhamento estratégico de TI, causados pelas alterações que ocorrem dentro da organização, já que esta se insere num ambiente externo competitivo. Assim, a melhor forma de assegurar que o alinhamento estratégico de TI seja alcançado e mantido em níveis adequados é pelo seu acompanhamento constante, tanto na fase de planejamento, quanto na fase de implementação (BRODBECK; HOPPEN, 2003). Além disso, alguns autores sugerem o uso de métricas adequadas para poder medi-lo, através de parâmetros que indiquem sua evolução e permitam corrigir eventuais alterações indesejadas (LUFTMAN, 2000; TEO; KING 1997).

Em resumo, o modelo conceitual teórico proposto mantém os principais conceitos encontrados nos modelos de alinhamento estratégico de TI, como: formulação e implementação, ajuste estratégico e integração funcional, processo contínuo e mudança no pensamento gerencial. Além disso, o modelo consolida conceitos propostos individualmente pelos autores estudados. O modelo explicita a importância das áreas de negócio e TI participarem mutuamente dos processos de planejamento, estarem integradas durante a execução da estratégia e possuírem meios eficazes de comunicação. O modelo também mostra os relacionamentos entre o alinhamento 
estratégico de TI e os resultados alcançados pelo uso da tecnologia da informação, destacando o papel da gestão dos projetos de TI na eficácia da TI e, por conseguinte, no próprio desempenho organizacional.

\section{Observações finais}

Este artigo partiu da importância da tecnologia da informação nas organizações e da necessidade de se alcançar o alinhamento estratégico entre negócios e TI.

Foram revisados, separadamente, os principais modelos de alinhamento estratégico de TI e, posteriormente, os mesmos foram triangularizados, de forma a se identificar pontos comuns e complementares.

A partir daí, um modelo conceitual teórico foi proposto. Entretanto, ainda que baseado em modelos validados e teorias comprovadas (GIL, 2002), o modelo conceitual aqui apresentado necessita ser validado cientificamente. Faz-se, portanto, necessário que a validação ocorra pela ligação do modelo teórico com dados oriundos de pesquisas empíricas (GIL, 2002).

Esta pesquisa ambicionou triangular diversos modelos de alinhamento estratégico de TI, de forma analíticoteórica e não empírica, o que limita a validade das suas conclusões (RAMOS; JOIA, 2007). Além disso, a própria análise é limitada pelo investimento de tempo e recursos que puderam ser utilizados (RAMOS; JOIA, 2007).

É inerente ao uso da estratégia de triangulação conceitual/teórica a emergência de divergências ou resultados contraditórios (FLICK, 1992; PATTON, 1990; SCANDURA; WILLIAMS, 2000; YIN, 2005). Tal fato pode estar ligado às limitações do estudo. Podem, por outro lado, revelar que o objeto em estudo se apresenta de forma diferente, quando enfocado de diversos ângulos (VERGARA, 2004). Na análise dos modelos foram identificadas posturas diferentes entre Teo e King (1997) e Kearns e Sabherwal (2006). Enquanto Teo e King (1997) afirmam que o conhecimento do negócio pelo executivo de TI é um fator-chave de influência na extensão do alinhamento estratégico de TI, Kearns e Sabherwal (2006) afirmam que o conhecimento de TI pela administração sênior da organização é um fator-chave de influência no alinhamento estratégico. Assim, as duas visões foram incluídas no modelo proposto, por serem entendidas como complementares, ao contribuírem para o melhor entendimento recíproco das áreas de negócios e TI e, conseqüentemente, para o alinhamento estratégico de TI.

Como recomendações gerenciais, este artigo sugere aos profissionais de TI que busquem conhecer os negócios de suas organizações como forma de ajudá-las a alcançar seus resultados pretendidos (TEO; KING, 1997). Não é adequado que eles se concentrem apenas nos aspectos técnicos de sua área. Ao contrário, devem se esforçar para aprender sobre os negócios de sua organização, pensando em formas de usar a TI para melhor embasá-los e/ou, até mesmo, modificá-los. Também para os executivos de negócio fica a indicação de procurarem conhecer mais sobre o papel da tecnologia da informação, suas aplicações e possibilidades (KEARNS; SABHERWAL, 2006). Eles também devem procurar incentivar a participação e o envolvimento de representantes da área de tecnologia da informação, desde cedo, nos processos de planejamento estratégico empresarial (CHAN et al, 1997).

Este artigo termina sugerindo que análises mais profundas sejam elaboradas. Dessa forma, deve ser considerado uma pesquisa em andamento, a qual certamente poderá ser refinada, não apenas com uma extensão empírica, mas, também, com um, ainda maior, aprofundamento teórico (RAMOS; JOIA, 2007). 


\section{Referências}

ANSOFF, H. I. Implanting strategic management. New Jersey: Prentice-Hall, Englewood Cliffs, 1984.

BRODBECK, A. F. et al. Práticas de alinhamento estratégico promovidas em organizações do estado do Rio Grande do Sul. In: Enanpad, 2005, Brasília. Anais... Porto Alegre: Enanpad, v.1, p.1-16, 2005.

; HOPPEN, N. Alinhamento estratégico entre planos de negócio e de tecnologia de informação: um modelo operacional para implementação. Revista de Administração Contemporânea, v.7, n.3, p.9-33, jul./set. 2003.

BRYNJOLFSSON, E. The productivity paradox of information technology. Communications of the ACM, v.36, p.66-77, Dec. 1993.

CHAN, Y. E. et al. Business strategic orientation, information systems strategic orientation, and strategic alignment. Information Systems Research, v.8, n.2, p-125-150, June 1997.

CIBORRA, C. U. De Profundis? Deconstructing the concept of strategic alignment. Scandinavian Journal of Information Systems, v.9, n.1, p.67-82, 1997.

FLICK U. Triangulation revisited: strategy of validation or alternative? Journal for the Theory of Social Behaviour, v.22, n.2, p.175-197, 1992.

GIL, A. C. Como elaborar projetos de pesquisa. 4.ed. São Paulo: Atlas, 2002.

HENDERSON, J.; VENKATRAMAN, N. Strategic alignment: leveraging information technology for transforming organizations. IBM Systems Journal, v.32, n.1, 1993.

HIRSCHHEIM, R.; SABHERWAL, R. Detours in the path toward strategic information systems alignment. California Management Review, v.44, n.1, p.87-108, 2001.

JOIA, L. A. Measuring intangible corporate assets: linking business strategy with intellectual capital. Journal of Intellectual Capital, v.1, n.1, p.68-84, 2000.

Geração de modelos heurísticos a partir de estudos de casos múltiplos: da teoria à prática. In: VIEIRA, M.; ZOUAIN, D. (Org.). Pesquisa qualitativa em administração. 2.ed. Rio de Janeiro: Editora FGV, 2006.

KEARNS, G. S.; SABHERWAL, R. Strategic alignment between business and information technology: a knowledge-based view of behaviors, outcome, and consequences. Journal of Management Information Systems, v.23, n.3, p.129-162, 2006.

LAURINDO, F. et al. O papel da tecnologia da informação (TI) na estratégia das organizações. Gestão \& Produção, São Paulo, v.8, n.2, p.160-179, ago. 2001.

LUCAS Jr., H. C.; BAROUDI, J. The role of information technology in organization design. Journal of Management Information Systems, v.10, n.4, p.9-23, mar. 1994.

LUFTMAN, J. Assessing business-IT alignment maturity. Communications of AIS, v.4, Dec. 2000.

ORLIKOWSKI, W. J.; ROBEY D. Information technology and the structuring of organizations. Information Systems Research, v.2, n.2, p.143-169, Jun. 1991.

PATTON, M. Q. Qualitative evaluation and research methods. $2^{\text {nd }}$ ed. Newbury Park, CA: Sage, 1990.

RAMOS, E. A.; JOIA, L. A. Articulando escolas de pensamento estratégico através da tecnologia da informação. Cadernos Ebape.BR, v.V, n.1, mar. 2007.

REICH, B. H.; BENBASAT, I. Measuring the linkage between business and information technology objectives. MIS Quarterly, v.20, n.1, p.55-81, Mar. 1996.

REZENDE, D. A. Alinhamento do planejamento estratégico da tecnologia da informação ao planejamento empresarial: proposta de um modelo e verificação da prática em grandes empresas brasileiras. Tese (Doutorado em Engenharia de Produção) - Programa de Pós-Graduação em Engenharia de Produção, Universidade Federal de Santa Catarina. 2002.

RIGONI, E. H. Alinhamento estratégico entre negócios e tecnologia da informação: práticas promovidas em empresas industriais da região Sul do Brasil. Dissertação (Mestrado em Administração) - Programa de Pós-Graduação em Administração, Universidade Federal do Rio Grande do Sul. 2006. 
SCANDURA T. A.; WILLIAMS E. A. Research methodology in management: current practices, trends, and implications for future research. The Academy of Management Journal, v.43, n.6, p.1248-1264, 2000.

STEVENSON, W. J. Estatística aplicada à administração. São Paulo: Harbra, 1986.

STRASSMANN, P. A. The squandered computer: evaluating the business alignment of information technologies. New Canaan, CT: The Information Economy Press, 1997.

TEO, T. S. H.; KING, W. R. Integration between business planning and information systems planning: an evolutionarycontingency perspective. Journal of Management Information Systems. v.14, n.1, p-185-214, 1997.

VERGARA, S. C. Métodos de pesquisa em administração. São Paulo: Atlas, 2004.

WEILL, P.; OLSON, M. Managing investment in information technology: mini case examples and implications, MIS Quarterly, v.13, n.1, p.3-17, Mar. 1989.

WINTER S. Knowledge and competence as strategic assets. In: KLEIN, D. (Ed.). The strategic management of intellectual capital, Woburn, MA: Butterworth-Heinemann, 1998.

YIN, R. Estudo de caso: planejamento e métodos. São Paulo: Bookman, 2005 